\title{
Potential Application of Lawsonia inermis L. (Lythraceae) Aqueous Extract as an Objectively Quantifiable Assay for Assessment of Viability of Protoscolices from Hydatid Cysts
}

\author{
Elsayed E. Elowni*, Ghada H. Abdelnabi, Mohamed F. Ahmad, Reem M. Badawi \\ Department of Parasitology, Faculty of Veterinary Medicine, University of Khartoum, Shambat, Khartoum, Sudan \\ Email: *elsayedelowni@gmail.com
}

How to cite this paper: Elowni, E.E., Abdelnabi, G.H., Ahmad, M.F. and Badawi, R.M. (2020) Potential Application of Lawsonia inermis L. (Lythraceae) Aqueous Extract as an Objectively Quantifiable Assay for Assessment of Viability of Protoscolices from Hydatid Cysts. Open Access Library Journal, 7: e6371. https://doi.org/10.4236/oalib.1106371

Received: April 29, 2020

Accepted: May 28, 2020

Published: June 1, 2020

Copyright $\odot 2020$ by author(s) and Open Access Library Inc.

This work is licensed under the Creative Commons Attribution International License (CC BY 4.0).

http://creativecommons.org/licenses/by/4.0/

\section{(c) (i) Open Access}

\begin{abstract}
Cystic echinococcosis, also known as hydatidosis, is a serious zoonotic disease. Protoscolices (PSCs) in hydatid cysts are the infective form of the tapeworm Echinococcus granulosus senso lato, an intestinal parasite of canines, particularly dogs. The cysts develop in a wide range of domestic and wild ungulates as intermediate hosts and humans as an aberrant host following incidental ingestion of parasite eggs. Canine hosts acquire infection with the adult parasite when they ingest with viscera fertile hydatid cysts containing PSCs. Problems, however, arise on how to assess the degree of this infectivity in the absence of a tangible method for measuring the success or failure of PSCs to develop inside the canine host. Critical evaluation of infectivity is essential to determine the relative importance of different species of intermediate hosts in parasite transmission and epidemiology of the disease. Several studies described staining with chemical reagents for assessment of viability of PSCs (defined as capacity of being alive), a property closely linked to infectivity. Lawsonia inermis L. (Lythraceae), commonly called "Henna", is a widely spread plant famous for having dyeing properties due to the presence of lawsone, a red-orange pigment extracted from plant leaves. The objective of this study was to examine the potential application of aqueous extract of plant leaves as a natural product for assessment of viability of PSCs using uptake/exclusion of plant pigment as criteria.
\end{abstract}

\section{Subject Areas}

Translational Medicine

Keywords

Lawsonia inermis, Henna, Hydatid Cysts, Protoscolices, Viability 


\section{Introduction}

Cystic echinococcosis (CE), also known as hydatidosis, is a serious zoonotic disease of great public health and economic importance worldwide [1]. It is caused by infection with the metacestode larval stage (hydatid cyst) of the tapeworm Echinococcus granulosus senso lato, an intestinal parasite of canines, particularly dogs. The cysts develop in a wide range of domestic and wild ungulates as intermediate hosts and humans as an aberrant host following incidental ingestion of parasite eggs [2]. The definitive canine hosts acquire infection with the parasite when they ingest with viscera fertile hydatid cysts containing protoscolices (PSCs). A fertile hydatid cyst normally contains thousands of PSCs. Problems; however, arise on how to assess the infectivity of these PSCs in absence of a tangible method for measuring the success or failure of these PSCs to develop inside the canine host. Critical assessment of PSC infectivity would, therefore, be essential to determine the relative importance of different species of intermediate hosts in parasite transmission and epidemiology of the disease. In this respect, several studies adopted in vitro staining techniques for assessment of viability of PSCs (defined as capacity of being alive), a property closely linked to infectivity. Various chemical stains such as eosin [3], trypan blue [4] or methylene blue [5] have been used for this purpose. There has been a remarkable increase of interest in natural product research over the past few decades for these products to be translated into practical applications in various fields such as medicine, agriculture, nutraceutical or cosmetics industries. Lawsonia inermis L. (Lythraceae), commonly called "Henna", is a widespread plant universally famous for having dyeing properties [6]. It is commonly used for personal adornment especially body art and in industry. The plant has also been described to have medicinal benefits [7] [8]. Henna's characteristic staining properties stem from the compound 2-hydroxy-1,4-naphthoquinone, known as lawsone; a red-orange pigment extracted from plant leaves [9]. The present study examines the potential application of aqueous extracts of $L$. inermis leaves for assessment of viability of PSCs from hydatid cysts taking uptake/exclusion of plant pigment as criteria.

\section{Materials and Methods}

\subsection{Parasite Material}

Hydatid cysts were recovered from the lungs of naturally infected camels slaughtered in a local market in Gezira State in Central Sudan. Intact cysts were transported to the parasitology laboratory at the Faculty of Veterinary Medicine, University of Khartoum. PSCs were recovered as a sediment following centrifugation of cyst fluid at $2000 \mathrm{rpm}$ for $3 \mathrm{~min}$ at $25^{\circ} \mathrm{C}$.

\subsection{Plant Extract}

Crude, newly harvested $L$. inermis sun-dried leaves of $35 \mathrm{~g}$ were obtained from a local Sudanese market in Khartoum. They were soaked in distilled water to give 
a $12.5 \% \mathrm{w} / \mathrm{v}$ mix. The preparation was kept in a refrigerator at $4^{\circ} \mathrm{C}$ for 24 hours and was subsequently strained through a fine mesh. Strained fluid was centrifuged at $2000 \mathrm{rpm}$ for 3 minutes to obtain a clear working solution. The $\mathrm{pH}$ (3.13) was determined using $\mathrm{pH}$ meter (AD8000 Bench Meter, Adwa Instruments, Hungary) just before use.

\subsection{Treatment}

$2 \mathrm{ml}$ of the working solution was added to protoscolex sediment in a test tube. The tube was gently agitated with slight movements and the mixture was left to stand for $10 \mathrm{~min}$, a period anticipated to enable the uptake or exclusion of plant pigment by PSCs. Contents were centrifuged at $1500 \mathrm{rpm}$ for $2 \mathrm{~min}$ at $25^{\circ} \mathrm{C}$ and the supernatant was discarded leaving a trickle of the working solution at the bottom of the tube. Samples were transferred with micropipettes to glass slides for microscopic examination. Control tests were performed with heat-killed PSCs [10] exposed to hot water at $60^{\circ} \mathrm{C}$ for $3 \mathrm{~min}$ in a water bath. For comparative purposes, PSCs were treated with eosin $0.1 \%$ aqueous solution, a stain widely used for assessment of viability of PSCs [11] [12]. Imaging was performed with a digital camera (OPTICAM 4083. B1) fitted to an OPTICA Srl B-193 light microscope (Ponteranica, Italy), at magnification 100 and $400 \times$.

\subsection{Statistical Analysis and Interpretation of Results}

The Echinococcus protoscolex has been described to have kinetically distinct molecular transfer systems for uptake of materials across the tegument (external body covering) [13]. Viability was assessed in terms of uptake/exclusion of plant pigments by viable (alive)/dead PSCs. Each of the experimental and control tests was replicated 5 times. Results were presented as frequencies of nominal variables in $2 \times 2$ contingency tables and analyzed by the Fisher exact probability test.

\section{Results}

Figure 1 shows the gross morphology of a non-stained Echinococcus protoscolex upon recovery from camel hydatid cyst showing the characteristic rostellar hooklets and calcareous corpuscles.

Normal PSCs exposed to L. inermis extract effectively excluded plant pigment when examined $10 \mathrm{~min}$ after exposure to extract (Figure 2(a), Figure 2(b)). No change in color could be observed between the PSCs as the test parasite and the surrounding extract medium.

In contrast, dead PSCs killed by heat before exposure to extract were permeable to the pigment acquiring the pigment distinctive color (Figure 3(a), Figure 3(b)). Frequencies for outcome of treatment (uptake/exclusion of plant pigment) were 0 and 5 for viable PSCs, respectively, as compared with frequencies of 5 and 0 , in this order, for dead PSCs, respectively. This difference between viable and dead PSCs in response to treatment was statistically significant $(p 0.0079)$. 


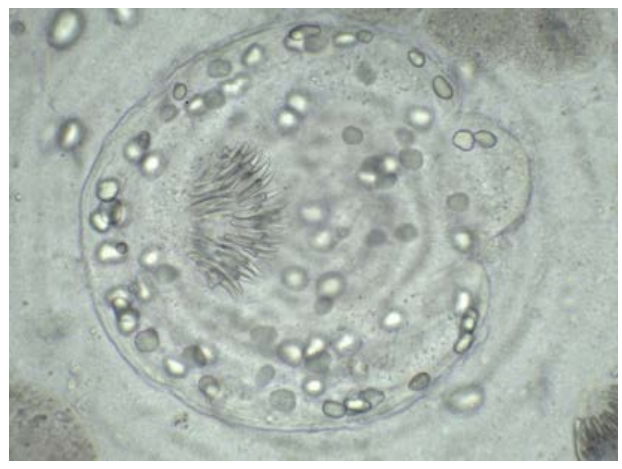

Figure 1. Normal invaginated unstained Echinococcus protoscolex from camel hydatid cyst $(400 \times)$.

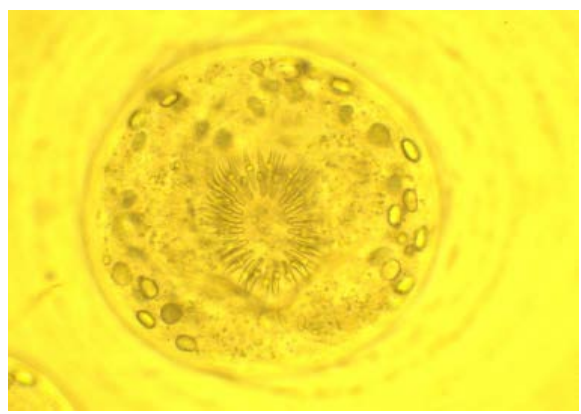

(a)

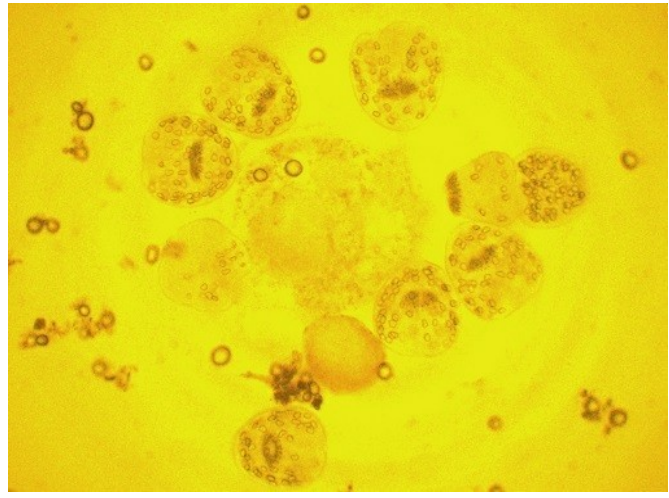

(b)

Figure 2. (a) Viable Echinococcus protoscolex following exposure to $L$. inermis leaves aqueous extract (400×); (b) Viable Echinococcus PSCs following exposure to L. inermis leaves aqueous extract $(100 \times)$.

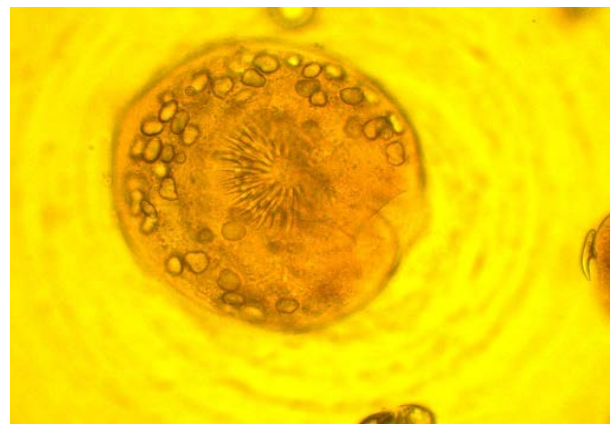

(a) 


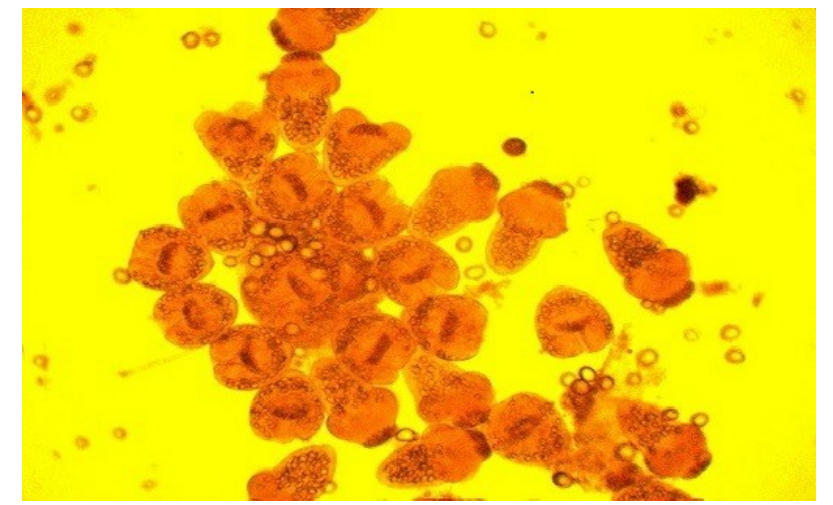

(b)

Figure 3. (a) Dead Echinococcus protoscolex following exposure to L. inermis leaves aqueous extract (400x); (b) Dead Echinococcus PSCs following exposure to L. inermis leaves aqueous extract $(100 \times)$.

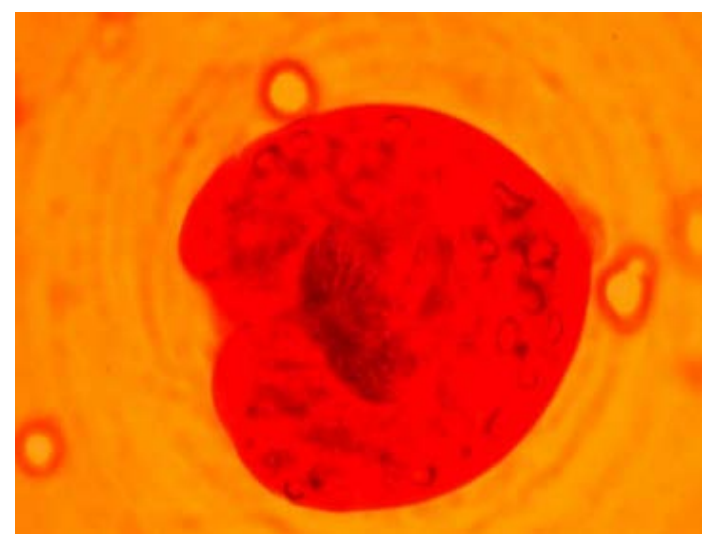

Figure 4. Dead Echinococcus protoscolex exposed to eosin stain (400×).

Performance of the extract was comparable to that of eosin as evidenced by uptake of the stain by dead PSCs (Figure 4).

\section{Discussion}

Among parasitic helminths, tapeworms, having no digestive tract, nor a respiratory or a blood-circulatory system, utilize the tegument alone as a metabolically active body cover capable of performing vital functions such as digestion, absorption as well as protection of the parasite [14] [15] [16]. According to Pappas [17], four distinct mechanisms, viz. pinocytosis, diffusion, active transport and facilitated diffusion, are implicated in nutrient uptake by tapeworms. The Echinococcus protoscolex, in particular, has been shown to have kinetically distinct molecular transfer systems for uptake of materials across the tegument [13]. Such properties enable the viability of PSCs to be assessed taking uptake/exclusion of materials as criteria. Results showed that viable PSCs invariably exclude L. inermis pigment in all 5 replicates. Control PSCs killed by heat, on the other hand, persistently acquire plant pigment. The actual mechanism by which a viable protoscolex excludes plant pigment and a dead protoscolex uptakes the 
pigment at the tegument cellular level, however, remains to be defined. It is proposed from the present study that application of $L$. inermis leaves aqueous extract has the potential to be employed effectively as a rapid, low-cost and an objectively quantifiable assay for assessment of viability of PSCs from hydatid cysts and that the distinction between viable and dead PSCs could be made in terms of exclusion or uptake of plant pigment, respectively.

\section{Conclusion}

Quantitative and qualitative analysis of the chemical composition of L. inermis leaves of Sudanese origin indicates presence of a multiplicity of components [18]. Further experiments are, therefore, necessary to standardize the method of assessment of viability by verifying the influence of such different components on the performance of the lawsone pigment as well the effect of the time of exposure to extract on PSCs.

\section{Conflicts of Interest}

The authors declare no conflicts of interest regarding the publication of this paper.

\section{References}

[1] The World Health Organization (2020) Fact Sheets Relating to Neglected Tropical Diseases (NTD). WHO, Geneva.

[2] Eckert, J., Deplazes, P., Craig, P.S., Gemmell, M.A., Gottstein, B., Heath, D., Jenkins, D., Kamiya, M. and Lightowlers, M. (2002) Echinococcosis in Animals: Clinical Aspects, Diagnosis and Treatment. In: Eckert, J., Gemmell, M.A., Meslin, F.X. and Pawlowski, Z.S., Eds., WHOIOIE Manual on Echinococcosis in Humans and Animals. A Public Health Problem of Global Concern, WHO/OIE, Paris, 73-100, Chapter 3.

[3] Miman, O., Aycan, O.M., Aydin, C. and Atambay, M. (2010) What Should Be the Concentration of Eosin to Qualification of Ideal Staining for Viability Determination on Hydatid Cyst? Türk Hijyen ve Deneysel Biyoloji Dergisi, 67, 21-26.

[4] Esfandiari, B. and Youssef, M.R. (2010) Comparison of Eosin and Trypan Blue Staining in Viability of Hydatid Cyst Protoscolices. Global Veterinaria, 4, 456-458.

[5] Elowni, E.E., Ahmad, M.F., Abdelnabi, G.H. and Badawi, R.M. (2019) Validation of the Methylene Blue Test for Assessment of Viability of Protoscolices from Hydatid Cysts. Open Veterinary Journal, 9, 172-176. https://doi.org/10.4314/ovj.v9i2.13

[6] Babili, F.E., Valentin, A. and Chatelain, C. (2013) Lawsonia inermis. Its Anatomy and Its Antimalarial, Antioxidant and Human Breast Cancer Cells MCF7 Activities. Pharmaceutica Analytica Acta, 4, 203. https://doi.org/10.4172/2153-2435.1000203

[7] Zumrutdal, E. and Ozaslan, M. (2012) A Miracle Plant for the Herbal Pharmacy; Henna (Lawsonia inermis). International Journal of Pharmacology, 8, 483-489. https://doi.org/10.3923/ijp.2012.483.489

[8] Sharma, R.K., Goel, A. and Bhatia, A.K. (2016) Lawsonia inermis Linn: A Plant with Cosmetic and Medical Benefits. International Journal of Applied Science and Biotechnology, 4, 15-20. https://doi.org/10.3126/ijasbt.v4i1.14728

[9] Dominici, L., Cerbone, B., Villarini, M., Pagiotti, R. and Moretti, M. (2013) In Vitro 
Genotoxicity Testing of Lawsonia inermis and Henna Extracts in HepG2 Cells by the Comet Assay. International Journal of Natural Product Science, 3, 12-21.

[10] Moazeni, M. and Alipour-Chaharmahali, M.R. (2011) Echinococcus granulosus: In Vitro Effectiveness of Warm Water on Protoscolices. Experimental Parasitology, 127, 14-17. https://doi.org/10.1016/j.exppara.2010.06.021

[11] Mahmoudvand, H., Dezaki, E.S., Kheirandish, F., Ezatpour, B., Jahanbakhsh, S. and Harandi, M.F. (2014) Scolicidal Effects of Black Cumin Seed (Nigella sativa) Essential Oil on Hydatid Cysts. Korean Journal of Parasitology, 52, 653-659. https://doi.org/10.3347/kjp.2014.52.6.653

[12] Mokhtaria, K. and Ammar, S.S.M. (2019) Frozen Hydatid Cysts Can Replace Incineration and Sterilize Cysts. Open Veterinary Journal, 9, 1-4.

https://doi.org/10.4314/ovj.v9i1.1

[13] Jeffs, S.A., Hurd, H., Allen, J.T. and Arme, C. (1978) Kinetics of Molecular Transfer across the Tegument of Protoscolices and Hydatid Cysts of Echinococcus granulosus and the Relevance of These Studies to Drug Targeting. In: Geerts, S., Kumar, V. and Brandt, J., Eds., Helminth Zoonoses, Springer, Dordrecht, 37-43.

https://doi.org/10.1007/978-94-009-3341-5_6

[14] Lumsden, R.D. and Specian, R. (1980) The Morphology, Histology and Fine Structure of the Adult Stage of the Cyclophyllidean Tapeworm Hymenolepis diminuta. In: Arai, H.P., Ed., Biology of the Tapeworm Hymenolepis diminuta, Academic Press, Cambridge, 157-280. https://doi.org/10.1016/B978-0-12-058980-7.50008-7

[15] Podesta, R.B. (1980) Concepts of Membrane Biology in Hymenolepis diminuta. In: Arai, H.P., Ed., Biology of the Tapeworm Hymenolepis diminuta, Academic Press, Cambridge, 505-549. https://doi.org/10.1016/B978-0-12-058980-7.50014-2

[16] Dalton, J.P., Skelly, P. and Halton, D.W. (2004) Role of the Tegument and Gut in Nutrient Uptake by Parasitic Platyhelminthes. Canadian Journal of Zoology, 82, 211-232. https://doi.org/10.1139/z03-213

[17] Pappas, P.W. (1985) Nutrient Uptake by Tapeworms. In: Gilles, R. and Gilles-Baillien, M., Eds., Transport Processes, Iono- and Osmoregulation, Proceedings in Life Sciences, Springer, Berlin, Heidelberg, 341-349. https://doi.org/10.1007/978-3-642-70613-4_29

[18] EL-Kamali, H.H., Abd el Lateef, M.M.A. and Hassan, A.W. (2018) Chemical Composition of Lawsonia inermis Cultivated under Sudanese Conditions-Existence of Chemotypes Species. International Journal of Advanced Biochemistry Research, 2, 1-3. https://doi.org/10.33545/26174693.2018.v2.i2a.13 